\title{
OBITUARY: Lidiano Bacchielli
}

In June this year 'Cyrenaicans' learnt with sorrow that Lidiano Bacchielli had died; unexpectedly, although it had been known for some months that he was in poor health. A pupil of Professor Sandro Stucchi at Urbino, and for many years a member of Stucchi's team in Libya, he was Professor of Classical Archaeology at Rome (La Sapienza) and at Urbino, had only very recently succeeded Stucchi as head of the Italian Mission to Cyrene, and, with youthful vigour (he was still in his early forties), seemed set to be moving ahead with it for a long term of well-planned work. His

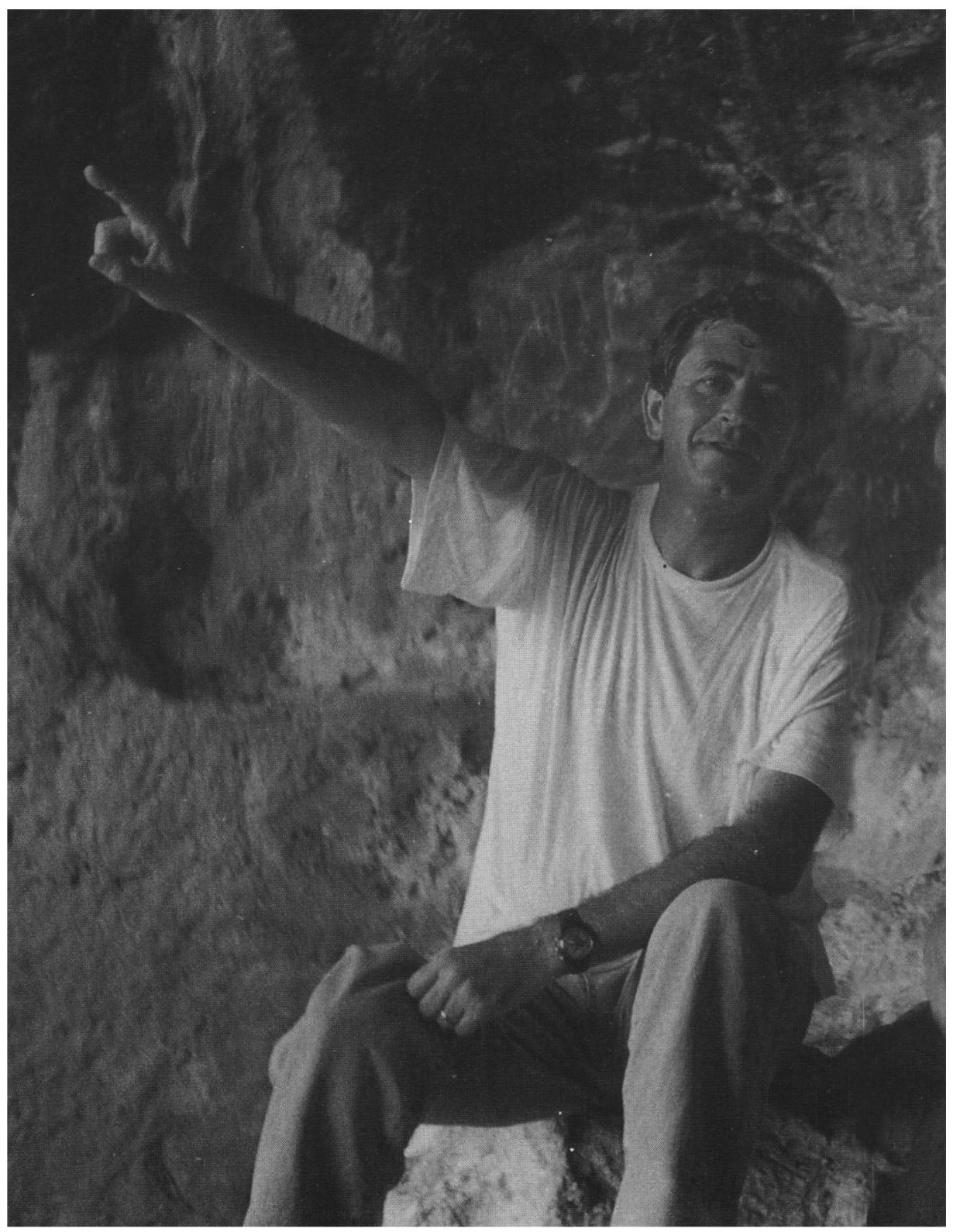


achievement is, in fact, already considerable. His bibliography is notable for contributions to the understanding of Cyrene's architecture and town planning as well as to the art history of the city and its territory; and he was quick to perceive the interest and importance of the artefacts produced by and for, and expressive of, the concerns of their Libyan population.

His work demonstrates the operation of a sensitively perceptive mind on systematically collected and accurately presented material; while his command of ancient literature, and his understanding of ancient history, regularly informed all his interpretations of archaeological evidence in a marked and illuminating way. Many members of the Society will remember the verve as well as the substance of the lecture which he gave in London on funerary art in ancient Cyrenaica (Libyan Studies 24 (1993) 77-116). His interests were wide (there was surely a touch of Renaissance Man in him); he was learned but always seeking to learn more, independent in his thinking but always keen to discuss with others, generous with young and old alike, a leader who aimed not to be authoritarian, a warm-hearted colleague and friend. The photograph, taken by a member of his team in Cyrenaica in summer 1995, catches him in the course of investigating a rock-cut feature on a Sunday holiday.

Joyce Reynolds 